\title{
Host range and phytotoxicity of Stemphylium solani, causing leaf blight of garlic (Allium sativum) in China
}

\author{
Lu Zheng • Rujing Lv • Tom Hsiang • \\ Junbin Huang
}

Received: 14 April 2008 / Accepted: 2 October 2008 / Published online: 21 October 2008

(C) KNPV 2008

\begin{abstract}
Since 2004, a new leaf blight disease on garlic of high severity has been observed in Dangyang County, Hubei province, China. Initial symptoms consisted of multiple, small, irregular to oval, white leaf spots, which enlarge to produce sunken purple lesions, sometimes surrounded by a bright yellow margin. As the disease progressed, lesions expanded and merged, resulting in withering of leaf tips. After isolation and pathogenicity testing, the causal agent of leaf blight of garlic was identified as Stemphylium solani from cultural and morphological characteristics, and subsequent analysis of the internal transcribed spacer region of ribosomal DNA. When fungal plugs of two $S$. solani isolates were inoculated onto 11 garlic cultivars and 20 other crop species, leaf spots appeared
\end{abstract}

L. Zheng $\cdot$ R. Lv $\cdot$ J. Huang $(\bowtie)$

The Key Lab of Plant Pathology of Hubei Province,

Huazhong Agricultural University,

Wuhan, Hubei 430070, China

e-mail: junbinhuang@mail.hzau.edu.cn

L. Zheng

e-mail: lucky@webmail.hzau.edu.cn

R. Lv

e-mail: lvrujing_wscn@163.com

T. Hsiang

Department of Environmental Biology,

University of Guelph,

Guelph ON N1G 2W1, Canada

e-mail: thsiang@uoguelph.ca on all inoculated plants, but two garlic cultivars (Qingganruanye and Ruanruanye) and three crop species (Capsicum annuum, Brassica napus and Amaranthus mangostanus) showed the smallest leaf spots. In cross-inoculation experiments, no indications of host specificity were observed, but $S$. solani isolated from garlic was generally the most virulent on five plant species, while the isolate from leek (Allium odorum) was generally the least virulent. Toxicity testing of the crude culture filtrates indicated that garlic isolates produced toxin(s) that were not heat-labile and induced different levels of phytotoxicity toward various garlic cultivars and crops.

Keywords Field crops · Garlic cultivars · ITS-rDNA · Pathogenicity · Toxin

\section{Introduction}

Garlic (Allium sativum) is one of the most widely grown vegetable crops in China, known for its therapeutic uses and as a flavouring agent since ancient times. Garlic contains allicin which has antioxidant and antibiotic properties. It is widely used both as a condiment and for improving human health. In China, this crop is cultivated mainly in Shandong, Sichuan and Hubei provinces. In central China, approximately half of the area's garlic crop is produced in Dangyang County, which is located in 
central-western Hubei province. In the 2005-2006 growing season, the planted area of garlic in Dangyang county was approximately 14,000 ha. From autumn 2004 to spring 2007, leaf blight symptoms initially consisting of small white spots (1-3 mm) enlarging to larger purple spots followed by blighting of the leaf tips were frequently observed on cultivated garlic leaves in Dangyang County, with the area of crop affected estimated to be over 7,000 ha. Garlic yield was reduced by $30 \%$ on average with up to $70 \%$ yield losses in some fields. Although there are other garlic diseases in this region, leaf blight of garlic has become the main disease limiting garlic production (Zheng et al. 2008).

Leaf blight of Allium caused by Stemphylium spp. was first reported in India (Rao and Pavgi 1975). More recently, it has been recorded in the USA (Miller et al. 1978), South Africa (Aveling and Naude 1992), Spain (Basallote et al. 1993), Brazil (Mehta 1998), Australia (Suheri and Price 2000a) and Egypt (Hassan et al. 2007). However, there are few studies on this disease in China. Stemphylium vesicarium has been reported as a pathogen that can cause white spots on the bolts of garlic (Shang et al. 1997). However, disease induced by this pathogen has not been reported to progress to enlarged purple spots on garlic as seen in the current disease outbreak. Previous research has found that $S$. botryosum, $S$. vesicarium (Boiteux et al. 1994), Alternaria porri and Cladosporium echinulatum (Pal and Basuchaudhary 1976) are causal agents of leaf blight of garlic. Stemphylium vesicarium and A. porri are the pathogens most frequently reported on the diseased leaves of garlic. These two pathogens can both cause white or purple spots of onion, and both can be present in the same spots and cause the same level of disease on onion (Suheri and Price 2000b).

We first reported the occurrence of $S$. solani on garlic in China in a brief disease report (Zheng et al. 2008). The purpose of the current research was to provide more detailed information on the disease outbreak and the causal agent, to test pathogenicity of isolates from different host species on a variety of crops and garlic cultivars under greenhouse conditions, and to determine if toxic metabolites are produced that could be involved in the production of the white spots that characterise this disease, as well as examining the host specificity of the putative toxin(s).

\section{Material and methods}

Isolation of the causal agent

In April 2005, diseased leaves with leaf blight symptoms were collected from fields in the main garlic production areas of Dangyang County in Hubei province, China. Small $(5 \times 5 \mathrm{~mm})$ sections of tissue were aseptically excised from margins of white spots, reddish purple spots, purple spots and withered leaf tips, and then surface-sterilised by soaking leaf pieces in $0.1 \%$ mercuric chloride solution for $1 \mathrm{~min}$ and rinsed in sterile distilled water (SDW) three times. The pieces were placed onto potato sugar agar (PSA, $2 \%$ sucrose, $1.2 \%$ agar) and incubated at $25^{\circ} \mathrm{C}$ on a $12 \mathrm{~h}$ light-dark cycle. The fungal growth was examined daily for up to 5 days. In addition, the most common fungal colonies were transferred onto fresh PSA slants and stored at $4^{\circ} \mathrm{C}$. No obvious cultural differences were seen between isolates from each symptomatic tissue type, and a single representative isolate from each type was chosen for further testing.

\section{Koch's Postulates}

Garlic plants (cv. Changbanpo) were sown in plastic pots containing sand and soil (3:1) which had been autoclaved at $121^{\circ} \mathrm{C}$ for $2 \mathrm{~h}$. Pathogenicity tests were performed with three $S$. solani isolates (DY-1, DY-5 and DY-6) which were isolated from white spots, purple spots or withered leaves, respectively. Inocula were prepared from conidial suspensions as follows. Cultures were grown on PSA for 7 days at $25^{\circ} \mathrm{C}$ under a 12-h photoperiod using near-ultraviolet (NUV) light. Conidia were dislodged from 5 day-old cultures by flooding with SDW and brushing gently, and then filtering through cheesecloth to remove mycelial fragments. The conidial suspension $\left(1 \times 10^{6}\right.$ conidia $\mathrm{ml}^{-1}$ ) of each isolate including several drops of $0.1 \%$ Tween 20 , was sprayed to run-off on 20 garlic leaves among seven 15 day-old plants with a compressed-air sprayer, and the plants were incubated at $25^{\circ} \mathrm{C}$ with a 12 -h photoperiod and $90 \%$ relative humidity (RH) in a controlled environment chamber (Ruihua model HP400GS, Wuhan, China). The healthy plants were sprayed with $0.1 \%$ Tween 20 without conidia as a control.

In addition, agar plug inoculum was prepared from 6 day-old cultures grown at $25^{\circ} \mathrm{C}$ on PSA medium. 
These $6 \mathrm{~mm}$ diam fungal plugs were inoculated singly onto 20 intact garlic leaves, with the mycelial surface in contact with the leaf. The inoculated garlic plants were kept in pots at $25^{\circ} \mathrm{C}$ with a 12 -h photoperiod and $90 \%$ RH in a controlled environment chamber. After 2 days of incubation, the fungal plugs were removed, and pots of garlic were transferred to the glasshouse with a 12 -h photoperiod at $25^{\circ} \mathrm{C}$. Disease was assessed every day for up to 14 days. At the end of this period, isolations were made from diseased tissue, and the pathogens compared to the original inoculated pathogens. The experiment was conducted twice.

\section{Pathogen morphology}

Three isolates (DY-1, DY-5 and DY-6) obtained from white spots, purple spots and withered leaves on garlic, respectively, and four isolates from other crops (Zea mays, Brassica chinensis, B. napus and Allium odorum) were initially examined for morphological characteristics. To obtain single-spore colonies, isolates were transferred onto sterile Petri dishes $(10 \mathrm{~cm}$ diam) containing PSA, and incubated at $25^{\circ} \mathrm{C}$ and $12 \mathrm{~h} / 12 \mathrm{~h}$ NUV light/darkness for 5 days. After incubation, a conidial suspension was obtained by flooding the dishes with $10 \mathrm{ml}$ of SDW and dislodging conidia with a pipette tip. One drop of conidial suspension was pipetted onto the surface of a Petri dish containing $2 \%$ water agar, and incubated for 1 day to allow for conidial germination. Single germinating conidia were transferred to fresh PSA media. For each isolate, five $6 \mathrm{~mm}$ diam plugs were transferred onto five plates of PSA and incubated for 5 days at $25^{\circ} \mathrm{C}$ and $12 \mathrm{~h} / 12 \mathrm{~h}$ NUV light/ darkness.

Cultures were examined for hyphal colour, colony colour, texture, margin characteristics and the development of pigments in the medium. Colony diameters were measured after 5, 6 and 7 days. The mean linear growth rate was calculated from sets of five plates, and determined by subtracting the colony diameter on day 5 from that on day 7 , divided by 2 . Fifty conidiophores and 50 conidia from each isolate were examined by microscopy. Length and width of conidia and conidiophores, number of transverse septa and constrictions, and number of longitudinal septa were compared to descriptions by Simmons (1969) and Ellis (1971). Morphological data were subjected to analysis of variance to detect significant differences $(P=0.05)$ between isolates. Where significant effects were found, means were compared by the test of least significant difference (LSD) at $P=0.05$.

Analysis of fungal rDNA-ITS sequence

Five $6 \mathrm{~mm}$ diam fungal plugs of each garlic isolate (DY-1, DY-5 and DY-6) were placed onto a previously autoclaved cellophane membrane on top of PSA medium. After 7 days of growth, mycelia were collected with a sterile blunt blade. Genomic DNA was extracted from each isolate by a CTAB method (Taylor et al. 1993) and stored at $-20^{\circ} \mathrm{C}$. The concentration was measured with a Biospec-mini DNA/RNA/Protein analyser (Shimadzu, Japan) and diluted to $10 \mathrm{ng}^{-1} \mathrm{l}^{-1}$ for PCR reactions.

Fungal rDNA from the ITS region was amplified with the primers ITS1 and ITS4 (White et al. 1990). DNA amplification was performed in a $50 \mu$ reaction mixture containing $5 \mu \mathrm{l} 10 \times \mathrm{PCR}$ buffer, $5 \mu \mathrm{l} 25 \mathrm{mM}$ $\mathrm{MgCl}_{2}, 2 \mu \mathrm{l} 2.5 \mathrm{mM}$ dNTP, $0.4 \mu \mathrm{l} 5 \mathrm{U} \mathrm{ml}^{-1}$ Taq DNA polymerase (Sangon, Shanghai, China), $1 \mu 125 \mathrm{mM}$ of each primer (ITS1 and ITS4), $10 \mathrm{ng}$ DNA template and $44.6 \mu \mathrm{l}$ sterile- $\mathrm{ddH}_{2} \mathrm{O}$. Amplifications were performed with a Ti-PCR thermal cycler system (Bio-RAD, USA) using the following programme: an initial denaturation step at $94^{\circ} \mathrm{C}$ for $4 \mathrm{~min}$, followed by 36 cycles of $94^{\circ} \mathrm{C}$ for $1 \mathrm{~min}, 54^{\circ} \mathrm{C}$ for $1 \mathrm{~min}, 72^{\circ} \mathrm{C}$ for $1 \mathrm{~min}$, and a final extension step at $72^{\circ} \mathrm{C}$ for $10 \mathrm{~min}$. Successful PCR reactions resulted in a single band observed on a $1 \%$ agarose gel (500 to $700 \mathrm{bp}$ ). PCR products were sent to Sangon (Shanghai) for purification and sequencing. Resulting ITS sequences were compared to the GenBank database using BLASTN, and the highest scoring matches were downloaded for closer comparison and alignment using DNAMAN (Version 5.2.2) (Perrone et al. 2004).

Pathogenicity of $S$. solani to garlic cultivars

To evaluate the pathogenicity on different garlic cultivars, isolates DY-1 and DY-5 of S. solani obtained from white spots and purple spots on garlic leaves, respectively, were used in this experiment. The isolates had been grown for 7 days on PSA under 12 h/12 h NUV light/ darkness. Fungal plugs ( $6 \mathrm{~mm}$ diam) were prepared and singly inoculated onto 30 leaves among ten plants of each of 11 garlic cultivars (Qingganruanye, Ruanruanye, Zhengyuezao, Changbanpo, Chengsuanzao-2, Ershuizao, Dusuan, Wenerzao, Chengsuanzao-3, 
Zixuan-1 and Hongqixing) at the three-leaf stage (20 days after sowing). Control plants received clean PSA plugs. Lesion diameter was measured 3 days after inoculation. The data were subjected to analysis of variance (ANOVA), and when significant treatment differences were found $(P=0.05)$, means were compared by the test of LSD. Fungal reisolations were conducted as previously described after symptoms appeared on inoculated plants. The experiment was repeated once.

Pathogenicity of $S$. solani to other plants

To determine the host range of two garlic isolates of S. solani, $6 \mathrm{~mm}$ diam fungal plugs of isolates DY-1 and DY-5 were prepared and inoculated onto leaves of the following plants: A. ascalonicum, A. odorum, Amaranthus mangostanus, Brassica campestris, $B$. chinensis, B. napus, Capsicum annuum, Coriandrum sativum, Gossypium hirsutum, Lycopersicon esculentum, Nicotiana tobacum, Oryza sativa, Pisum sativum, Raphanus sativus, Solanum tuberosum, Sorghum vulgare, Spinacia oleracea, Triticum aestivum, Vicia faba and Zea mays. Garlic was inoculated as a positive check, whereas PSA plugs served as negative controls. The plant species selected for this experiment are crops commonly grown in Hubei province. Between 20 to 30 leaves among ten plants were inoculated for each crop. The inoculated plants were incubated in a dew chamber for $48 \mathrm{~h}$ at $28^{\circ} \mathrm{C}$, and then the plugs removed. The size of leaf spots was examined 3 days after inoculation, and the causal organism was reisolated from lesions on PSA to confirm the presence of the pathogen. The experiment was repeated once and the data were subjected to ANOVA. When significant treatment differences were found $(P=0.05)$, means were compared by the test of LSD.

Cross-inoculation of $S$. solani from Allium sativum, $A$. odorum, Brassica chinensis, B. napus and Zea mays

To test the virulence of different $S$. solani isolates from different hosts, between 20 to 30 leaves among 10 plants per host species were inoculated with $S$. solani isolate DY-5 from A. sativum, isolate DY-M-1 from Z. mays, isolate DY-C-1 from B. chinensis, isolate DY-L-1 from A. odorum, or isolate DY-R-1 from $B$. napus in separate tests using $6 \mathrm{~mm}$ diam fungal plugs. Between 18 to 20 leaves per host were treated with PSA plugs as controls. From each isolate by host combination, the leaves were separated into three blocks in a randomised complete block design. All inoculated plants were incubated in a dew chamber for $48 \mathrm{~h}$ at $28^{\circ} \mathrm{C}$, after which plugs were removed. The diameter of leaf spots was recorded 3 days after inoculation and the pathogen was reisolated from the lesions. The experiment was repeated once and the data were subjected to ANOVA. When significant treatment differences were found $(P=0.05)$, means were compared by the test of LSD.

Phytotoxicity test and host specificity of the toxin

To test for toxin production, $S$. solani isolates DY-1 and DY-5 were grown on PSA at $25^{\circ} \mathrm{C}$. Two $6 \mathrm{~mm}$ diam fungal plugs were cut from the margin of each colony and transferred into $250 \mathrm{ml}$ flasks containing $100 \mathrm{ml}$ of autoclaved potato sugar broth. The flasks were incubated for $10 \mathrm{~d}$ at $25^{\circ} \mathrm{C}$ with shaking $150 \mathrm{rpm}$. The broth was filtered through four layers of cheesecloth and Whatman no. 1 filter paper, and then stored overnight at $4{ }^{\circ} \mathrm{C}$ before use. Precipitates were removed by centrifugation at $8,000 \mathrm{rpm}$ for $10 \mathrm{~min}$. A portion of the supernatant was autoclaved at $121^{\circ} \mathrm{C}$ for $15 \mathrm{~min}$.

Culture filtrates were tested on potted plants by first making a puncture wound on adaxial leaf surfaces with a syringe needle, and then applying $50 \mu \mathrm{l}$ of solution onto the surface of each wound. Sterile non-inoculated potato sugar broth was used as a control. For each garlic cultivar and crop tested, 20 fully expanded 20 to 30 day-old leaves were treated with either crude filtrate or autoclaved filtrate. After treatment, plants were kept at $90 \% \mathrm{RH}$ at $28^{\circ} \mathrm{C}$ for daily observation over 5 days. Bioassays and host specificity tests were carried out on the 11 garlic cultivars and 20 other crops listed above. The experiments were conducted twice and the data were subjected to ANOVA. When significant treatment differences were found $(P=0.05)$, means were compared by the test of LSD.

\section{Results}

Morphology of fungal isolates and completion of Koch's Postulates

Forty-three isolates with cultural characteristics similar to Stemphylium spp. were obtained from disease samples. These isolates included 31 garlic isolates 
and 12 isolates originating from other four crops. Only species of Stemphylium were isolated from white spots or reddish purple spots on garlic leaves. Moreover, $100 \%$ of successful isolations from white spots or reddish purple spots, and over $50 \%$ of isolations from purple spots produced Stemphylium spp., while the rest of the isolates from these tissues were identified as species of Alternaria. Withered leaf tips gave Alternaria sp. over $75 \%$ of the time, and only $10 \%$ yielded Stemphylium spp. (Table 1). Furthermore, $100 \%$ of successful isolations from white spots on four other crops were identified as Stemphylium spp.

One Stemphylium isolate from each of the typical symptoms (white spot, purple spot, withered tip) on garlic diseased leaves and white spots on four other crops was selected for cultural studies (DY-1, DY-5, DY-6, DY-M-1, DY-C-1, DY-R-1 and DY-L-1, respectively). Morphological characteristics of the conidia and conidiophores of these seven isolates were similar. On PSA, conidiophores were up to $173 \mu \mathrm{m}$ long. Conidia were pointed at the swollen apex of each conidiophore, brown, oblong-ellipsoid or clavate, straight, smooth, with one to three dark coloured transverse septa and distinctly constricted at median septa, two to seven longitudinal or oblique septa, 29$58(45) \times 14-28(22) \mu \mathrm{m}$ (mean) and mean length/width ratio was 2.03 . Naturally diseased leaves of garlic were incubated under high humidity at $28^{\circ} \mathrm{C}$, and many conidia were produced, ranging in size from $27-48$ $(39) \times 15-30(21) \mu \mathrm{m}$.

Initial colonies of isolates on PSA were composed of dense, villiform and white mycelium when incubated at $25^{\circ} \mathrm{C}$ in $12 \mathrm{~h} / 12 \mathrm{~h}$ dark/light photoperiod, but after 4 days on PSA, the centres of the colonies turned grey, and agar in the Petri dishes became stained yellow-brown throughout. Mean linear growth rates at $25^{\circ} \mathrm{C}$ for seven isolates were $2.4,2.6,2.7,2.5$,
2.4, 2.8 and $2.2 \mathrm{~mm} \mathrm{day}^{-1}$. Based on cultural characteristics and fungal morphology (Table 2), the isolates were identified as $S$. solani.

All three garlic $S$. solani isolates tested were pathogenic to garlic leaves at the three-leaf stage, and the pathogenicity was similar among the isolates, with disease severity less using conidial suspensions than with fungal plugs. Leaf blight lesions became visible on all inoculated leaves within $48 \mathrm{~h}$ after inoculation by fungal plugs, and the initial lesions were small, oval, white and irregularly scattered on the leaves. As the lesions aged and extended, they became purple, surrounded by a bright yellow margin. After 8 days, they coalesced and covered large areas, resulting in necroses of the entire leaf. After inoculation with conidial suspensions, white spots appeared on $75 \%$ of the leaves after 4 days, but did not develop much further in following 2 weeks. No lesions appeared on control plants sprayed with water or inoculated with PSA plugs. Koch's Postulates were completed by re-isolating from the surfacesterilised tissue of inoculated plants, and recovering fungi with the same morphological features as those inoculated. Results of the two repeated experiments were similar.

\section{rDNA-ITS sequence data}

Genomic DNA (80 to $120 \mathrm{ng} \mu \mathrm{l}^{-1}$ ) was extracted from isolates DY-1, DY-5 and DY-6. Successful PCR reactions with primer ITS1 and ITS4 resulted in single bands of approximately 550 bp observed on a $1 \%$ agarose gel. Fragments were sent for sequencing, and all isolates had almost identical sequence in their overlapping region (no more than two base differences in any pairwise comparison). Comparison with sequences in GenBank showed $99 \%$ similarity with S. solani

Table 1 Isolation of the causal organism from different samples collected November 2006 to January 2007 from the garlic cv. Changbanpo in Dangyang County of Hubei province, China, grown on PSA for 7 days at $25^{\circ} \mathrm{C}$

\begin{tabular}{lcrc}
\hline Symptom & Isolations attempted & \multicolumn{2}{l}{ Number of isolates and percentage (\%) } \\
\cline { 3 - 4 } & & Stemphylium spp. & Alternaria spp. \\
\hline White spots & 30 & $1(3.3 \%)$ & $0(0 \%)$ \\
Reddish-purple spots & 24 & $9(37.5 \%)$ & $0(0 \%)$ \\
Purple spots & 33 & $18(54.6 \%)$ & $10(30.3 \%)$ \\
Withered tips & 30 & $3(10.0 \%)$ & $23(76.7 \%)$ \\
\hline
\end{tabular}


Table 2 Morphology of conidia and conidiophores of Stemphylium solani isolated from Allium sativum and other crops

\begin{tabular}{|c|c|c|c|c|c|c|}
\hline \multirow[t]{2}{*}{ Isolate } & \multirow[t]{2}{*}{ Host } & \multicolumn{3}{|c|}{ Conidial morphology ${ }^{a}$} & \multicolumn{2}{|c|}{ Conidiophores $^{\mathrm{a}}$} \\
\hline & & Length $(\mu \mathrm{m})$ & Width $(\mu \mathrm{m})$ & Length/width ratio & Length $(\mu \mathrm{m})$ & Width $(\mu \mathrm{m})$ \\
\hline DY-1 & A. sativum white spots & $47 \pm 14$ & $23 \pm 7$ & 2.04 & $143 \pm 21$ & $6 \pm 1$ \\
\hline DY-5 & A. sativum purple spots & $45 \pm 11$ & $23 \pm 5$ & 1.96 & $150 \pm 19$ & $6 \pm 1$ \\
\hline DY-6 & A. sativum withered tips & $42 \pm 13$ & $20 \pm 7$ & 2.10 & $147 \pm 15$ & $6 \pm 1$ \\
\hline DY-M-1 & Zea mays & $49 \pm 12$ & $24 \pm 5$ & 2.04 & $155 \pm 23$ & $6 \pm 1$ \\
\hline DY-C-1 & Brassica chinensis & $44 \pm 11$ & $22 \pm 6$ & 2.00 & $162 \pm 17$ & $6 \pm 1$ \\
\hline DY-R-1 & B. napus & $39 \pm 11$ & $20 \pm 7$ & 1.95 & $153 \pm 16$ & $6 \pm 1$ \\
\hline DY-L-1 & A. odorum & $46 \pm 12$ & $22 \pm 6$ & 2.09 & $159 \pm 26$ & $6 \pm 1$ \\
\hline
\end{tabular}

\footnotetext{
${ }^{a}$ Mean and standard deviation based on 50 observations. An ANOVA showed no significant differences $(P>0.05)$ between isolates for
} any of the characteristics assessed.

(AF203450), and the three sequences differed by less than two bases from the GenBank sequence in the ITS region.

Pathogenicity of $S$. solani to garlic cultivars

Results from the repeated experiments were in agreement and the data are combined in Table 3. The two isolates (DY-1 and DY-5) of $S$. solani from garlic were pathogenic to all 11 garlic cultivars tested. When garlic isolates were inoculated onto garlic cultivars using agar plugs, white, circular leaf spots developed after 2 days and were similar to initial symptoms observed on diseased plants in the field. The virulence spectrum of these two isolates of $S$. solani was similar. Hence, results shown in Table 3 are means of both isolates. The inoculated pathogen was re-isolated from the lesions, and was morphologically identical to the isolates from the original diseased leaf tissues from the field. A $100 \%$ disease incidence was recorded on all garlic cultivars with both isolates. None of the control plants treated with clean agar plugs developed symptoms. After 3 days of incubation, differences in disease severity among the cultivars were noticeable, with cvs Qingganruanye and Ruanruanye exhibiting slightly smaller white spots than other cvs, while purple lesions developed on cvs Chengsuanzao-3, Zixuan-1 and Hongqixing, which were more susceptible to $S$. solani. In moist chamber conditions, conidia, conidiophores and mycelia of $S$. solani developed on tissues with all types of lesions.

Pathogenicity of $S$. solani to other plants

The results were similar from two repeated experiments and are combined in Table 4. Leaf spots developed on all 21 plants 3 days after inoculation with isolates DY-1 and DY-5. However, symptoms were slight on $C$. annuum, $B$. napus and $A$. mangostanus. None of the control plants treated with PSA plugs developed symptoms. Stemphylium solani was re-isolated from disease leaves which had been inoculated.

\section{Cross-inoculation of $S$. solani}

Thirty day-old plants of $A$. sativum, A. odorum, $B$. chinensis and $B$. napus and $Z$. mays, were separately inoculated with five isolates of $S$. solani originally isolated from each of these plant hosts in all possible

Table 3 Virulence of Stemphylium solani isolates DY-1 and DY-5 to various garlic cultivars, and sensitivity of the cultivars to culture filtrates

\begin{tabular}{llc}
\hline Garlic cultivar & \multicolumn{2}{l}{ Lesion diameter $(\mathrm{mm})^{\mathrm{a}}$} \\
\cline { 2 - 3 } & S. solani & Culture filtrate \\
\hline Hongqixing & $17.3 \pm 1.3 \mathrm{a}$ & $19.8 \pm 1.9 \mathrm{a}$ \\
Zixuan-1 & $17.2 \pm 1.6 \mathrm{a}$ & $17.0 \pm 1.1 \mathrm{ab}$ \\
Chengsuanzao-3 & $15.7 \pm 1.0 \mathrm{ab}$ & $19.1 \pm 1.2 \mathrm{a}$ \\
Wenerzao & $14.2 \pm 1.4 \mathrm{bc}$ & $17.7 \pm 2.5 \mathrm{ab}$ \\
Changbanpo & $12.2 \pm 3.6 \mathrm{~cd}$ & $10.3 \pm 1.4 \mathrm{c}$ \\
Ershuizao & $11.3 \pm 1.9 \mathrm{de}$ & $16.0 \pm 1.2 \mathrm{~b}$ \\
Dusuan & $10.8 \pm 1.1 \mathrm{de}$ & $15.4 \pm 1.2 \mathrm{~b}$ \\
Zhengyuezao & $10.2 \pm 1.4 \mathrm{de}$ & $10.8 \pm 2.3 \mathrm{c}$ \\
Chengsuanzao-2 & $9.3 \pm 1.0 \mathrm{e}$ & $15.8 \pm 2.9 \mathrm{~b}$ \\
Qingganruanye & $4.5 \pm 1.6 \mathrm{f}$ & $2.9 \pm 0.9 \mathrm{~d}$ \\
Ruanruanye & $3.8 \pm 1.5 \mathrm{f}$ & $5.6 \pm 1.3 \mathrm{~d}$ \\
\hline
\end{tabular}

${ }^{a}$ Inoculated plants (three-leaf stage at 20 days) were evaluated after 3 days for lesion diameter. Means followed by a letter in a common are not significantly different at $P=0.05$ in a test of LSD. 
Table 4 Pathogenicity of Stemphylium solani isolates DY-1 and DY-5 to various crops and toxicity of culture filtrates

\begin{tabular}{|c|c|c|c|}
\hline \multirow[t]{2}{*}{ Crop } & \multirow[t]{2}{*}{ Species } & \multicolumn{2}{|c|}{ Lesion diameter $(\mathrm{mm})^{\mathrm{a}}$} \\
\hline & & S. solani & Culture filtrate \\
\hline Onion & Allium ascalonicum cv. Sijixiaocong & $45.6 \pm 3.2 \mathrm{a}$ & $43.0 \pm 2.2 \mathrm{a}$ \\
\hline Tobacco & Nicotiana tabacum & $22.5 \pm 1.2 \mathrm{a}$ & $13.3 \pm 2.3 \mathrm{~b}$ \\
\hline Maize & Zea mays cv. Tiannuo-1 & $19.5 \pm 2.5 \mathrm{a}$ & $17.8 \pm 2.1 \mathrm{a}$ \\
\hline Leek & Allium odorum cv. Chaojixuejiu & $18.7 \pm 3.5 \mathrm{a}$ & $18.5 \pm 1.6 \mathrm{a}$ \\
\hline Garlic & Allium sativum cv. Changbanpo & $17.1 \pm 2.0 \mathrm{a}$ & $18.4 \pm 1.9 \mathrm{a}$ \\
\hline Potato & Solanum tuberosum & $16.4 \pm 2.0 \mathrm{a}$ & $10.3 \pm 1.0 \mathrm{~b}$ \\
\hline Spinach & Spinacia oleracea cv. Quannengdaye & $13.6 \pm 2.5 \mathrm{a}$ & $3.9 \pm 0.8 \mathrm{~b}$ \\
\hline Radish & Raphanus sativus & $13.2 \pm 0.6 \mathrm{a}$ & $12.3 \pm 1.0 \mathrm{a}$ \\
\hline Tomato & Lycopersicon esculentum cv. Hongfushi & $12.1 \pm 1.7 \mathrm{a}$ & $9.6 \pm 1.2 \mathrm{a}$ \\
\hline Chinese cabbage & Brassica chinensis cv. Shangdongsihao-F1 & $11.9 \pm 3.7 \mathrm{a}$ & $15.1 \pm 1.6 \mathrm{a}$ \\
\hline Coriander & Coriandrum sativum & $10.8 \pm 3.4 \mathrm{a}$ & $7.8 \pm 1.6 \mathrm{a}$ \\
\hline Rape & Brassica campestris & $10.0 \pm 2.7 \mathrm{~b}$ & $15.6 \pm 1.1 \mathrm{a}$ \\
\hline Pea & Pisum sativum & $8.7 \pm 1.7 \mathrm{~b}$ & $16.7 \pm 1.6 \mathrm{a}$ \\
\hline Cotton & Gossypium hirsutum & $8.6 \pm 1.5 \mathrm{a}$ & $9.6 \pm 1.3 \mathrm{a}$ \\
\hline Sorghum & Sorghum vulgare & $8.4 \pm 1.0 \mathrm{a}$ & $4.4 \pm 0.9 \mathrm{~b}$ \\
\hline Wheat & Triticum aestivum $\mathrm{cv}$. Zheng98 & $7.7 \pm 1.6 \mathrm{a}$ & $0.0 \pm 0.0 \mathrm{~b}$ \\
\hline Broad bean & Vicia faba & $7.2 \pm 1.7 \mathrm{~b}$ & $15.8 \pm 1.1 \mathrm{a}$ \\
\hline Rice & Oryza sativa $\mathrm{cv}$. Yuanfengzao & $6.6 \pm 1.1 \mathrm{a}$ & $5.3 \pm 1.3 \mathrm{a}$ \\
\hline Pepper & Capsicum annuum cv. Xianglaerjintiao & $4.7 \pm 1.4 \mathrm{a}$ & $5.7 \pm 1.1 \mathrm{a}$ \\
\hline Rape & B. napus cv. Huayouza-12 & $4.5 \pm 1.6 \mathrm{~b}$ & $15.0 \pm 0.8 \mathrm{a}$ \\
\hline Amaranth & Amaranthus mangostanus & $4.2 \pm 1.9 \mathrm{a}$ & $4.8 \pm 1.1 \mathrm{a}$ \\
\hline
\end{tabular}

${ }^{\mathrm{a}}$ Inoculated plants (grown up to a month) were evaluated after 3 days for lesion diameter. Means within a row followed by the same letter are not significantly different at $P=0.05$ in a test of LSD.

pairwise combinations. All plants developed leaf spots and necrotic symptoms. Among the isolates of S. solani, the garlic isolate was generally most virulent on these five plants, while the isolate from leek (A. odorum) was generally least virulent (Table 5). There was no evidence for host specificity, since the diagonal in Table 5 (top left to bottom right) where an original host and an isolate from that host were matched, did not result in larger lesions than other pairings.

\section{Phytotoxicity tests}

Isolates of S. solani (DY-1 and DY-5) produced culture filtrates which were phytotoxic to needle-wounded garlic leaves. The induced damage was similar with or without autoclaving of the filtrate. No symptoms were observed on garlic leaves using droplets of potato sugar liquid medium on wound sites. The application of the crude filtrates on wounded garlic leaves was

Table 5 Cross-pathogenicity of Stemphylium solani isolated from various hosts inoculated onto various crop species

\begin{tabular}{llccccc}
\hline Isolate & \multirow{2}{*}{ Host } & \multicolumn{2}{l}{ Lesion diameter(mm) ${ }^{\mathrm{a}}$} & & \\
\cline { 3 - 7 } & & Allium odorum & Allium sativum & Brassica chinensis & Brassica napus & Zea mays \\
\hline DY-L-1 & A. odorum & $6.1 \pm 0.9 \mathrm{~b}$ & $7.0 \pm 1.0 \mathrm{~cd}$ & $2.1 \pm 0.2 \mathrm{c}$ & $0.9 \pm 0.1 \mathrm{~b}$ & $8.6 \pm 3.1 \mathrm{~d}$ \\
DY-5 & A. sativum & $20.4 \pm 2.4 \mathrm{a}$ & $16.9 \pm 4.0 \mathrm{a}$ & $10.3 \pm 3.9 \mathrm{a}$ & $2.3 \pm 0.3 \mathrm{a}$ & $25.0 \pm 3.0 \mathrm{a}$ \\
DY-C-1 & B. chinensis & $5.9 \pm 0.9 \mathrm{~b}$ & $10.1 \pm 2.0 \mathrm{bc}$ & $5.8 \pm 1.3 \mathrm{~b}$ & $1.0 \pm 0.3 \mathrm{~b}$ & $16.0 \pm 5.2 \mathrm{bc}$ \\
DY-R-1 & B. napus & $8.2 \pm 1.5 \mathrm{~b}$ & $4.3 \pm 1.2 \mathrm{~d}$ & $2.1 \pm 0.2 \mathrm{c}$ & $1.3 \pm 0.6 \mathrm{~b}$ & $17.7 \pm 1.0 \mathrm{bc}$ \\
DY-M-1 & Z. mays & $7.5 \pm 3.3 \mathrm{~b}$ & $13.2 \pm 1.9 \mathrm{ab}$ & $2.9 \pm 0.7 \mathrm{bc}$ & $1.5 \pm 0.6 \mathrm{ab}$ & $22.4 \pm 3.3 \mathrm{ab}$ \\
\hline
\end{tabular}

${ }^{a}$ Lesion diameter was measured 3 days after inoculation on 30 day-old seedlings of A. sativum, A. odorum, B. chinensis and B. napus and Zea mays. Means within a column followed by a letter in common are not significantly different at $P=0.05$ in a test of LSD. 
followed by the development of a limited sunken white lesion within $48 \mathrm{~h}$. The symptoms caused by the culture filtrate were identical with those produced by the pathogen.

Eleven garlic cultivars were tested for their reaction to culture filtrate, and all of them were susceptible. The culture filtrate induced the same symptoms on all garlic cultivars tested 3 days after treatment. However, variation in disease severity among the different garlic cvs was observed. The results are presented in Table 3 showing that cvs Qingganruanye and Ruanruanye were less susceptible to the culture filtrate, while cvs Zhengyuezao and Changbanpo were moderately susceptible (Table 3). A high correlation coefficient between cultivar sensitivity and sensitivity to the culture filtrate was observed ( $r=0.87, P=0.0004)$. Among the 21 different plant species, only Triticum aestivum was considered resistant to the culture filtrate, whereas other plants were susceptible (Table 4). In all cases, treatment with potato sugar broth induced no symptoms. In most cases among the 21 different species, there were no significant differences in lesion diameter induced by S. solani isolates compared to the culture filtrates (Table 4).

\section{Discussion}

Aside from the brief previous disease report (Zheng et al. 2008), this is the first report of Stemphylium leaf blight of garlic caused by S. solani. Previous reports had stated that Stemphylium species associated with garlic are $S$. vesicarium and S. botryosum (Pal and Basuchaudhary 1976). Furthermore, this pathogen was isolated from white leaf spots on $A$. odorum, $B$. chinensis and $B$. napus and $Z$. mays, which is also the first report of its occurrence on these species.

The garlic leaf blight occurred in sporadic outbreaks in various fields across Dangyang County beginning in 2004 and each year thereafter. Field surveys and subsequent laboratory tests of garlic crops in Hubei province indicated that the three typical symptoms, namely white spots, purple spots and withered tips, were all caused by the same pathogen. During our research in 2006, the white spots were first found on garlic leaves at the end of October. After several days of heavy rainfall and mist, $75 \%$ of the white spots turned to purple and the spots enlarged. Moreover, Stemphylium leaf blight on garlic in the field may be confused with initial symptoms of Botrytis leaf spot since both diseases exhibit similar initial symptoms with small white spots. Despite these similarities, these two diseases can be discerned if the symptoms are examined carefully, because Botrytis leaf spot initially has a small white necrotic centre surrounded by a light green halo, whereas Stemphylium leaf blight has no halo (Lv et al. 1998). White spots on garlic and onion caused by Botrytis sp. had been reported by Segall and Newhall (1960), and growers in the area have reported greyish powdery masses on the leaf surfaces associated with leaf spots; however, Botrytis sp. was not isolated from diseased garlic samples in the present research.

The identification of $S$. solani on the basis of morphological characteristics and sporulation is a challenging task. Nevertheless, the number of septa and constrictions in conidia, and the size of conidia and conidiophores are useful criteria to differentiate $S$. solani isolates from other Stemphylium species (Simmons 1969; Ellis 1971). The length/width ratio of conidia produced by these isolates (2.03) is similar to the L/W ratio of 2 for $S$. solani reported by Weber (1930), whereas other Stemphylium species have ratios such as 1.5 ( $S$. botryosum; Simmons 1985) or 3.0 (S. lycopersici; Ellis 1971). The size of the conidiophores and conidia as reported by Ellis (1971) was 130 to $200 \times 4$ to $7 \mu \mathrm{m}$ and 35 to $55 \times 18$ to $28 \mu \mathrm{m}$, respectively. The reported sizes are similar to those found with our isolates of $S$. solani. In identifying this garlic leaf blight pathogen as $S$. solani, comparisons were also made to descriptions by Mehta (1998), who had examined colony characteristics, and the same results were found, namely that colonies were slow-growing on the artificial medium and produced a yellow-brown pigment with age that turned medium deep red. Additionally, as reported by Mehta (1998), pigment production was variable and reduced after transferring for several generations, and this was observed with isolates in this study. Although the morphological characteristics and conidial dimensions of the causal organism on artificial medium were very similar to S. solani as described by Weber (1930), the conidia of our isolates had smoother walls in contrast to verrucose walls of $S$. solani. However, Stemphylium species can show variation in conidial morphology due to environmental factors (Simmons 1969). Confirmation 
of the identity of the pathogen was sought by sequence analysis of rDNA. The results showed that the ITS sequences were virtually identical among three isolates from garlic cv. Changbanpo and almost identical to the $S$. solani sequence in GenBank. Thus, the identification of this pathogen as $S$. solani is supported by DNA sequence data.

Stemphylium solani was reported as a leaf blight pathogen on numerous crops, including Lycopersicon esculentum (Weber 1930), Solanum lycocarpum (Boiteux et al. 1993), Gossypium hirsutum (Mehta 1998), S. tuberosum (Mehta 2001) and Capsicum annuum (Kim et al. 2004), but it has not been isolated from other crops. When the garlic isolates of $S$. solani were inoculated onto cultivars of a large range of crop species, typical leaf blight symptoms also appeared. On the basis of these inoculation experiments, we concluded that the isolates of $S$. solani that caused leaf blight of garlic in Hubei province were not hostspecific.

Our results also showed that $S$. solani was pathogenic to all 21 tested plants, and this is a broader host range than previous reports. Similar findings were reported by Mehta and Brogin (2000) with $S$. solani, which showed pathogenicity to a range of 11 host plants in pathogenicity tests. Subsequent further investigations in 2007 near the originally sampled diseased garlic fields revealed that $S$. solani could be isolated from white leaf spots of $Z$. mays, $A$. sativum, A. odorum, B. chinensis and B. napus, which provided some confirmation for our pathogenicity tests. Furthermore, wide host ranges have also been documented for other species of Stemphylium which were capable of infecting taxonomically unrelated host genera. All of the 11 garlic cultivars tested were susceptible to $S$. solani but differed in disease severity. Cultivars Qingganruanye and Ruanruanye were the most resistant to the pathogen, as well as less sensitive to damage induced by its culture filtrate. A strong correlation was found between cultivar sensitivity and sensitivity to the culture filtrate. Testing with culture filtrates might be a quick and useful method in breeding and selecting for resistance to Stemphylium leaf blight of garlic.

Bioassays for toxic activity by leaf infiltration of seedlings at the three-leaf stage revealed that $S$. solani isolates could induce white spot symptoms on needlewounded garlic leaves that were indistinguishable from those induced by the fungus. All garlic cultivars and other crops tested were susceptible to the pathogen. Similar host specificity of toxins from other pathogens have been demonstrated using nonhosts and hosts of Pyrenophora graminea (Haegi and Porta-Puglia 1995), P. teres (Smedegard-Petersen 1977), Rhizoctonia solani (Vidhyasekaran et al. 1997), S. versicarium (Singh et al. 1999), Septoria glycies (Song et al. 1993) and Diaporthe phatolorum (Lalitha et al. 1989). The toxin was non-host specific but exhibited differential phytotoxicity towards various plants. Mehta and Brogin (2000) reported that S. solani of cotton produced a host-specific toxin which was specific to their principal cotton cultivars and not other plants, which is in contrast to our results where we found some damage by the S. solani toxin(s) on 20 other crop species in addition to the original host, garlic. Stemphylium solani produces one or more phytotoxic compounds capable of producing symptoms normally associated with leaf spot disease. Furthermore, the phytotoxicity of the culture filtrate was not inactivated by autoclaving demonstrating that the active component is likely to be neither an enzyme nor a protein.

The non-host-specific toxin(s) of $S$. solani appeared to be associated with general pathogenicity of the fungus, because the sensitivity to the toxin(s) of each garlic cultivar was correlated with the extent of disease development in inoculation tests. Conidia are able to penetrate through foliar stomates of garlic leaves within $8 \mathrm{~h}$ after inoculation (unpublished data), but first symptoms are observed after 4 days, whereas culture filtrates are able to induce white spot symptoms after $48 \mathrm{~h}$. This suggests that the toxin(s) are produced after pathogen invasion and colonisation in garlic leaves. In inoculation experiments, veinal necrosis was also observed suggesting that the toxin(s) are water-soluble and contribute to lesion expansion through the water transport system.

In conclusion, leaf blight of garlic recently observed in China is caused by $S$. solani and consists of three typical symptoms, namely small white leaf spots, larger purple spots and withered leaf tips. The pathogen has a wide host range and was isolated from white spot symptoms on a variety of field crops such as rape, leek, Chinese cabbage and maize. It showed pathogenicity to 21 crop species tested, and differential virulence to various garlic cultivars. Furthermore, garlic isolates of $S$. solani were found to produce toxin(s) which were not heat-labile and could induce 
white leaf spot symptoms with $48 \mathrm{~h}$ on a range of garlic cultivars and other crops. Further study is needed of these nonspecific toxin(s) and their role in pathogenesis by this pathogen.

Acknowledgements This work was supported by The Key Research Project (2006AA201B06) of Hubei province, China, and by the Ontario Ministry of Agriculture, Food and Rural Affairs, Ontario, Canada.

\section{References}

Aveling, T. A. S., \& Naude, S. P. (1992). First report of Stemphylium vesicarium on garlic in South Africa. Plant Disease, 76, 426.

Basallote, M. J., Prados, A. M., Perez de Algaba, A., \& Melero, J. M. (1993). First report in Spain of two leaf spots of garlic caused by Stemphylium vesicarium. Plant Disease, 77, 952.

Boiteux, L. S., Henz, G. P., \& Giordano, L. B. (1993). Solanum lycocarpum, a natural host of Stemphylium solani. Plant Disease, 77, 846.

Boiteux, L. S., Lima, M. F., Menezes, J. A., \& Lopes, C. A. (1994). A garlic (Allium sativum) leaf blight caused by Stemphylium vesicarium in Brazil. Plant Pathology, 43, 412-414. doi:10.1111/j.1365-3059.1994.tb02704.x.

Ellis, M. B. (1971). Dematiaceous hyphomycetes. Kew: Commonwealth Mycological Institute.

Haegi, A., \& Porta-Puglia, A. (1995). Purification and partial characterization of a toxic compound produced by Pyrenophora graminea. Physiological and Molecular Plant Pathology, 46, 429-444. doi:10.1006/pmpp.1995.1033.

Hassan, M. H. A., Allam, A. D. A., Abo-Elyousr, K. A. M., \& Hussein, M. A. M. (2007). First report of Stemphylium leaf blight of onion caused by Stemphylium vesicarium in Egypt. Plant Pathology, 56, 724. doi:10.1111/j.1365-3059.2007.01581.x.

Kim, B. S., Yu, S. H., Cho, H. J., \& Hwang, H. S. (2004). Grey leaf spot in peppers caused by Stemphylium solani and $S$. lycopersici. The Plant Pathology Journal, 20, 85-91.

Lalitha, B., Snow, J. P., \& Berggren, G. T. (1989). Phytotoxin production by Diaporthe phaseolorum var. caulivora, the causal organism of stem canker of soybean. Phytopathology, 79, 499-504. doi:10.1094/Phyto-79-499.

Lv, P. K., Li, M. Y., \& Wu, J. W. (1998). Atlas of insect pests and diseases of vegetable crops in China. Beijing: Agricultural Publishing House.

Mehta, Y. R. (1998). Severe outbreak of Stemphylium leaf blight, a new disease of cotton in Brazil. Plant Disease, 82, 333-336. doi:10.1094/PDIS.1998.82.3.333.

Mehta, Y. R. (2001). Genetic diversity among isolates of Stemphylium solani from cotton. Fitopatologia Brasileira, 26, 703-709.

Mehta, Y. R., \& Brogin, R. L. (2000). Phytotoxicity of a culture filtrate produced by Stemphylium solani of cotton. Plant Disease, 84, 838-842. doi:10.1094/PDIS.2000.84.8.838.

Miller, M. E., Taber, R. A., \& Amador, J. M. (1978). Stemphylium blight of onion in South Texas. Plant Disease Reporter, 62, 851-853.

Perrone, G., Susca, A., Stea, G., \& Mulè, G. (2004). PCR assay for identification of Aspergillus carbonarius and Asper- gillus japonicus. European Journal of Plant Pathology, 110, 641-649. doi:10.1023/B:EJPP.0000032403.08921.49.

Pal, A. K., \& Basuchaudhary, K. C. (1976). A new leaf blight of garlic caused by Cladosporium echlnulatum (Berk) de Vries, from Varanasi, Uttar Pradesh. Current Science, 45, 739.

Rao, N. N., \& Pavgi, M. S. (1975). Stemphylium leaf blight of onion. Mycopathologica, 56, 113-118. doi:10.1007/ BF00472582.

Segall, R. H., \& Newhall, A. G. (1960). Onion blast or leaf spotting caused by species of Botrytis. Phytopathology, 50, 76-82.

Shang, H. S., Wang, S. Q., Zuo, J. Z., \& Zhao, J. Y. (1997). The causal agent of white spot and rot of garlic bolt. Acta Agriculturae Boreali-occidentalis Sinica, 6, 73-76.

Simmons, E. G. (1969). Perfect states of Stemphylium. Mycology, 61, 1-26. doi:10.2307/3757341.

Simmons, E. G. (1985). Perfect states of Stemphylium. II. Sydowia, 38, 284-293.

Singh, P., Bugiani, R., Cavanni, P., Nakajima, H., Kodama, M., Otani, H., et al. (1999). Purification and biological characterization of host-specific SV-toxins from Stemphylium vesicarium causing brown spot of European pear. Phytopathology, 89, 947-953. doi:10.1094/PHYTO.1999.89.10.947.

Smedegard-Petersen, V. (1977). Isolation of two toxins produced by Pyrenophora teres and their significance in disease development of netspot blotch of barley. Physiological Plant Pathology, 10, 203-211. doi:10.1016/00484059(77)90024-8.

Song, H. S., Lim, S. M., \& Clark, J. M. (1993). Purification and partial characterization of a host-specific pathotoxin from culture filtrates of Septoria glycines. Phytopathology, 83, 659-661. doi:10.1094/Phyto-83-659.

Suheri, H., \& Price, T. V. (2000a). Stemphylium leaf blight of garlic (Allium sativum) in Australia. Australasian Plant Pathology, 29, 192-199. doi:10.1071/AP00034.

Suheri, H., \& Price, T. V. (2000b). Infection of onion leaves by Alternaria porri and Stemphylium vesicarium and disease development in controlled environments. Plant Pathology, 49, 377-384. doi:10.1046/j.13653059.2000.00458.x.

Taylor, B. H., Manhart, J. R., \& Amsoino, R. M. (1993). Isolation and characterization of plant DNA. In B. R. Glick, \& J. E. Thompson (Eds.), Methods in plant molecular biology and biotechnology (pp. 37-47). Boca Raton, FL: CRC.

Vidhyasekaran, P., Ponmalar, T. R., Samiyappan, R., Velazhahan, R., Vimala, R., Ramanathan, A., et al. (1997). Host-specific toxin production by Rhizoctonia solani, the rice sheath blight pathogen. Phytopathology, 87, 1258-1263. doi:10.1094/PHYTO.1997.87.12.1258.

Weber, F. G. (1930). Gray leaf spot of tomato caused by Stemphylium solani sp. nov. Phytopathology, 20, 513-518.

White, T. J., Bruns, T., Lee, S., \& Taylor, J. (1990). Amplification and direct sequencing of fungal ribosomal RNA genes for phylogenetics. In M. A. Innis, D. H. Gelfand, J. J. Sninsky, \& T. J. White (Eds.), PCR Protocols: a guide to methods and applications (pp. 315-322). San Diego: Academic.

Zheng, L., Huang, J. B., \& Hsiang, T. (2008). First report of leaf blight of garlic (Allium sativum) caused by Stemphylium solani in China. Plant Pathology, 57, 380. doi:10.1111/j.1365-3059.2007.01724.x. 